\title{
Intraoperative endoscopic observation of sclerotomy site after cannula removal for 23-gauge vitrectomy
}

This article was published in the following Dove Press journal:

Clinical Ophthalmology

28 February 2014

Number of times this article has been viewed

\section{Taiichi Hikichi \\ Hirokuni Kitamei \\ Shoko Kosaka \\ Shoko Shioya \\ Kimitaka Takami}

Ohtsuka Eye Hospital, Sapporo, Japan

Correspondence: Taiichi Hikichi

Ohtsuka Eye Hospital, Kita-16 Nishi-4,

Kita-ku, Sapporo 00 I-00 16, Japan

Tel +8 I I I74752 II

Fax +8 II I757 5223

Email taiichi-hikichi@hokkaido.med.or.jp
Background: The purpose of this study was to determine the incidence of vitreous incarceration in sclerotomy after cannula removal during 23-gauge vitrectomy.

Methods: Thirty-seven eyes underwent 23-gauge sutureless vitrectomy. Oblique sclerotomies were made parallel to the limbus and tangentially to the sclera. Once past the trocar sleeve, the angle was changed to 90 degrees perpendicular to the surface and the trocar and cannula inserted. Vitreous gel was removed until the intraocular edge of the infusion cannula was free from the gel. The cannula was extracted with insertion of a light probe. The sclerotomy site was evaluated endoscopically through another cannula in 32 eyes; in five eyes, another infusion tube was inserted into the cannula to maintain intraocular pressure, the original infusion was removed, and the sclerotomy site observed.

Results: No vitreous incarceration occurred in 30 (94\%) eyes when one cannula was removed with insertion of a light probe, and minimal incarceration occurred in two (6\%) eyes. No incarceration occurred in five eyes with observation of the infusion site.

Conclusion: The incidence of vitreous incarceration is low when a light probe or vitreous cutter is inserted. Inserting the light probe through the cannula during its removal and creating an oblique sclerotomy may reduce vitreous incarceration.

Keywords: cannula, endoscopy, sclerotomy site, trocar, 23-gauge vitrectomy

\section{Introduction}

Sutureless self-sealing sclerotomies created during 23-gauge or 25-gauge vitrectomy have increased in popularity since their introduction ${ }^{1-3}$ and are considered safe in patients with various vitreoretinal pathologies. ${ }^{4-7}$ It has been speculated that a trocar and cannula inserted into a sclerotomy site, which is generally done during microincision vitrectomies, reduces stress on the sclerotomy site. ${ }^{8,9}$ Parameters ${ }^{10-12}$ have been identified relating to the sclerotomy architecture and the surgery that affect the integrity of the sclerotomy closure, such as vitreous incarceration, which may function as an incisional plug, favoring postoperative sclerotomy closure, ${ }^{13}$ however, vitreous incarceration has also been associated with postoperative complications, such as peripheral retinal tears as a result of postoperative vitreous contraction, acute endophthalmitis due to the presence of an incisional vitreous wick that may facilitate entry of bacteria into the vitreous cavity, ${ }^{14-17}$ and fibrovascular proliferation, which is considered a major risk factor for recurrent vitreous hemorrhage in patients with diabetes. ${ }^{18}$

Some investigators ${ }^{19-24}$ prefer creation of oblique sclerotomy incisions rather than straight incisions to prevent leakage through the sutureless wounds. Recent studies ${ }^{24-26}$ have reported the potential importance of wound construction in sutureless vitrectomy. 
In addition, inserting a solid instrument through the cannula during its extraction may reduce vitreous entrapment ${ }^{13,27}$ as well as peripheral retinal tears and acute endophthalmitis.

Although it has not been a long time since microincision sutureless vitrectomy became popular, knowledge about the procedure has increased and the instrumentation has evolved to reduce complications. Thus, we speculated that the incidence of vitreous incarceration may decrease after microincision sutureless vitrectomy with creation of oblique sclerotomy incisions. We evaluated the incidence of vitreous incarceration at the sclerotomy site after removal of the cannula by inserting a solid instrument through the cannula using the endoscope ${ }^{20,28}$ at the end of surgery.

\section{Patients and methods}

The study protocol was approved by the Institutional Review Board for Human Subjects Research at Ohtsuka Eye Hospital, and adhered to the tenets of the Declaration of Helsinki. Thirty-seven consecutive eyes from 32 patients (13 men, 19 women) of mean age 66 (range 52-78) years underwent 23 -gauge sutureless vitrectomy to treat preretinal membrane. There were no exclusion criteria.

All patients underwent phacoemulsification and a surgical procedure under local anesthesia. Phacoemulsification was performed before vitrectomy in all cases. A 23-gauge vitrectomy was performed using a Grieshaber trocar cannula set (Alcon Laboratories Inc., Fort Worth, TX, USA) including a trocar and metal cannula, which differed from the previous generation that included a polymer cannula, and an Accurus 400 VS vitreous machine (Alcon Laboratories Inc.,) under peribulbar anesthesia in all cases. The conjunctiva and Tenon's capsule were displaced anteriorly away from the intended sclerotomy site using forceps to avoid direct communication between the entry sites. All incisions were created obliquely $3.5-4.0 \mathrm{~mm}$ posterior to the limbus. The eyes were penetrated tangential to the limbus (approximately 30 degrees) with a so-called one-step procedure. Once past the trocar sleeve, the angle was changed to 90 degrees perpendicular to the surface, and the trocar and cannula were inserted into the eye. The infusion cannula was placed in the inferotemporal quadrant, and two other cannulas were placed in the superotemporal and superonasal areas.

Triamcinolone acetonide $10 \mathrm{mg} / \mathrm{mL}$ (MaQaid ${ }^{\circledR}$; Wakamoto Co, Ltd, Tokyo, Japan) was injected intravitreally to improve the visibility of the vitreous gel (Figure 1), which was removed until the intraocular edge of the infusion cannula was free from vitreous gel (Figure 2). At the end of surgery in 32 eyes, one cannula used for insertion of the vitreous

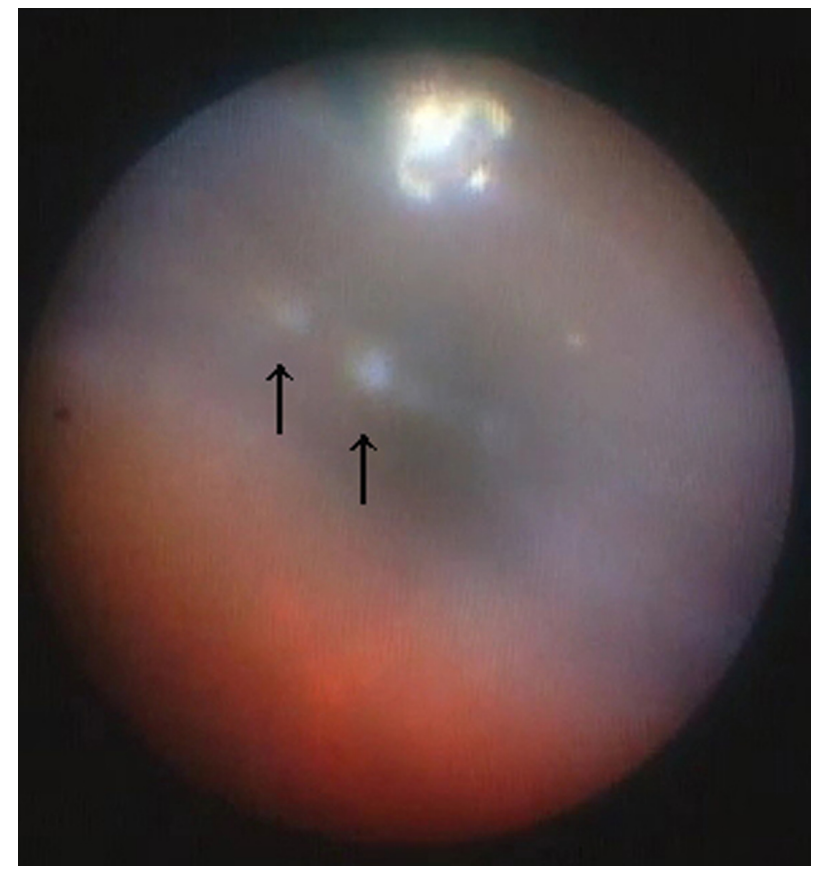

Figure I Intraoperative endoscopic findings with a 23-gauge cannula inserted into the eye through the pars plana. Vitreous gel entrapping triamcinolone acetonide particles (arrows) can be observed around the intraocular edge of the cannula.

cutter or light probe was removed slowly by insertion of a light probe following the angled path over the light probe to prevent vitreous from following the cannula up the wound and producing a vitreous wick. The light probe was then removed slowly and the sclerotomy site was massaged gently

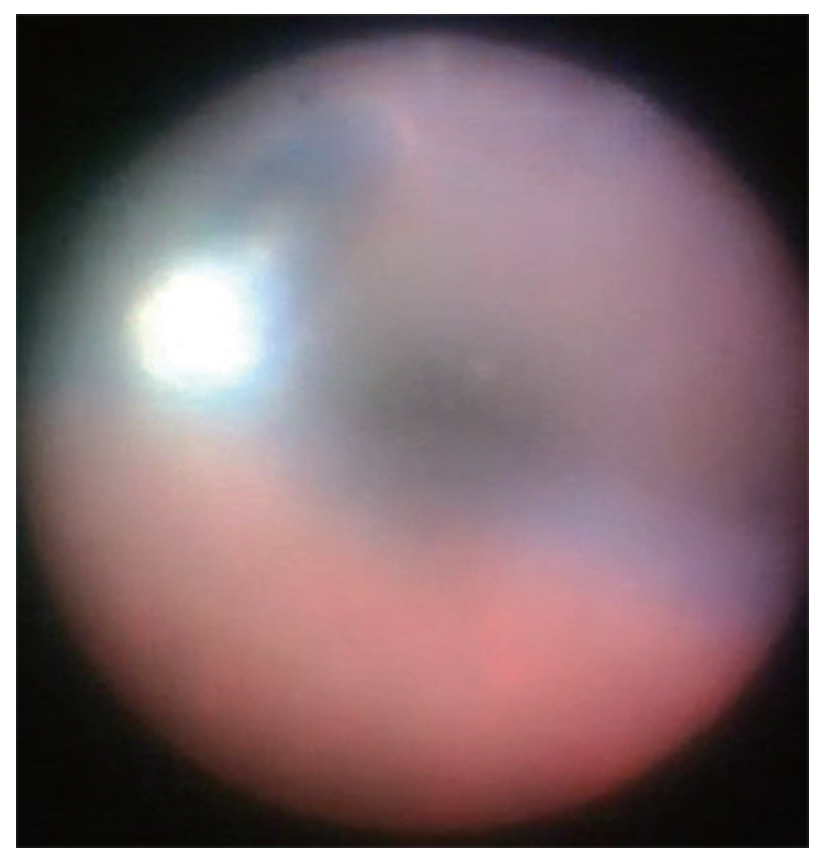

Figure 2 Intraoperative endoscopic findings with a 23-gauge cannula inserted into the eye through the pars plana. The intraocular edge of the cannula is free from vitreous gel. 
with a cotton swab and inspected for leakage. The intraocular sclerotomy site was observed for vitreous incarceration using a 23-gauge endoscope (Solid Fiber catheter AS-61; FiberTech Co, Ltd, Tokyo, Japan) inserted through the other cannula. If the cannula used for insertion of the vitreous cutter was removed, its sclerotomy site was observed using the endoscope inserted through the cannula used for insertion of the light probe. Sclerotomies used for insertion of the vitreous cutter or light probe were observed in 16 eyes. In a further five eyes, at the end of surgery, another infusion tube was inserted into the cannula after the light or cutter probe was removed; the original infusion tube and cannula placed inferotemporally were then removed and the sclerotomy site was observed using the endoscope inserted through the other cannula. When removing the cannula, the irrigation fluid from the infusion cannula was stopped in all cases. One surgeon (TH) performed all procedures. Fluid-air or fluid-gas exchange was not performed in any of the eyes.

\section{Results}

Intraoperative endoscopic observation provided an image around the pars plana and the pars plicata without scleral indentation (Figure 3). It was easy to observe the cannula and site of intravitreal cannula insertion intraoperatively (Figure 2).

During observation of the sclerotomy site after one cannula was removed with insertion of a light probe in 32 eyes, no vitreous gel incarceration was seen in 30 (94\%) eyes. Minimal vitreous strands were incarcerated in two $(6 \%)$ eyes (endoscopic images were not presented due to their low quality); in these eyes, the strands were observed at the

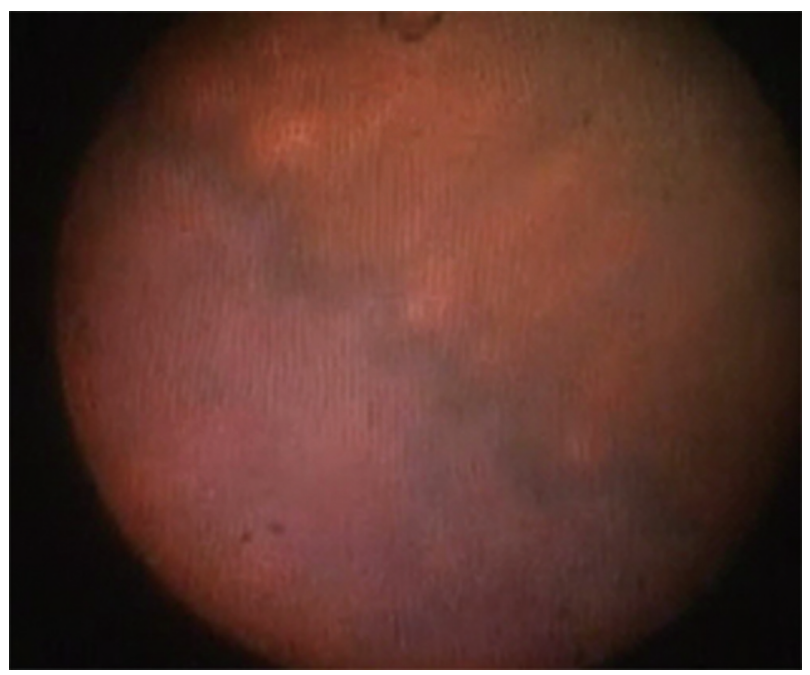

Figure 3 Intraoperative endoscopic findings in the ora serrata and pars plana. sclerotomy site through which the light probe was inserted, and in the other eye at the sclerotomy site through which the vitreous cutter was inserted. Figure 4 shows a small round area of depigmentation at the pars plana, indicating no vitreous incarceration in the sclerotomy site. During observation of the sclerotomy site after the infusion cannula was removed, no vitreous incarceration was seen in five eyes. The mean ( \pm standard deviation) surgical time was $28 \pm 4$ minutes.

Basically, the frequency of exchange of instruments inserted into the cannula during the surgery was kept at a minimum. Thus, injection of triamcinolone acetonide, insertion of forceps for membrane peeling, and insertion of endoscope were opportunities to exchange instruments inserted into the cannula during the surgery.

\section{Discussion}

Our intraoperative observations show the incidence of vitreous incarceration at the oblique sclerotomy site after removal of a cannula with insertion of a light probe. Although it was difficult to determine if our $6 \%$ incidence of vitreous incarceration was low, this rate is similar to that reported in 2010 by Chen et al, ${ }^{29}$ who studied 35 eyes undergoing a 23 -gauge procedure combined with 25-gauge infusion vitrectomy; two (5.7\%) of their eyes had minimal vitreous incarceration at scleral sites evaluated by anterior segment optical coherence tomography. More recent studies ${ }^{13,27}$ using a porcine model in which a light pipe was inserted into the cannula during its removal reported a significant reduction in the amount of postoperative vitreous incarceration compared with sclerotomies in which cannulas were removed with a plug inserted. A number of studies have

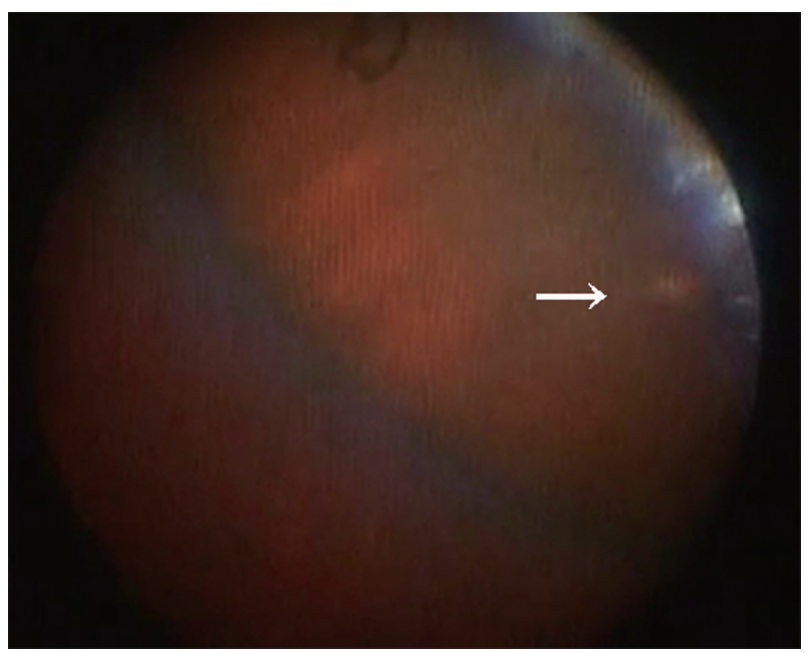

Figure 4 Intraoperative endoscopic finding of depigmentation (arrow) at the sclerotomy site after the cannula was removed. Although it is difficult to confirm no vitreous incarceration in the photograph, the absence of triamcinolone acetonide particles suggests that there is no vitreous incarceration at the sclerotomy site. 
emphasized the importance of creating oblique incisions rather than straight incisions ${ }^{19-24,26-30}$ and reported that angled incisions were grossly and histopathologically superior, and the same findings were seen on anterior segment optical coherence tomography or ultrasound biomicroscopy images. Teixeira et $\mathrm{al}^{24}$ found no vitreous incarceration in sclerotomy sites that were created obliquely.

Reported incidence rates for vitreous incarceration at the sclerotomy site of microincision sutureless vitrectomy are variable. ${ }^{11,13,24,28-33}$ Using ultrasound biomicroscopy, Gutfleisch et $\mathrm{al}^{30}$ reported that the incidence of vitreous incarceration decreased from $40 \%$ to $20 \%$ at the sclerotomy sites using a 23-gauge two-step system compared with a sclerotomy site using a 23-gauge one-step system; in their study, the cannulas were simply removed. López-Guajardo et al, ${ }^{11}$ who performed ultrasound biomicroscopy to evaluate 25-gauge sclerotomies, reported vitreous incarceration in $72 \%$ of cases. Using endoscopy, Nagpal et $\mathrm{al}^{28}$ found more vitreous clogging in the inner lip of the sclerotomies in transconjunctival sutureless vitrectomies than in conventional 20 -gauge vitrectomies. In a study of sclerotomy sites in rabbits, ${ }^{32}$ vitreous incarceration occurred in $59.4 \%$ of cases. Inoue et $\mathrm{al}^{33}$ found vitreous strands incarcerated at the sclerotomy site in porcine eyes by Miyake-Apple view and in human eyes using endoscopy. These inconsistencies in incidence rates for vitreous incarceration may be due to the different surgical techniques used and the differences between human eyes and experimental models. To reduce vitreous incarceration in sclerotomies, we shaved the vitreous gel around the cannulas and inserted a light probe into the cannulas when removing them. The structure of the sclerotomy is also associated with the incidence of vitreous incarceration. We tried to create longer oblique scleral incisions and reduce the incisional damage during surgery to ensure good self-sealing. The method of evaluating vitreous incarceration at the sclerotomy site is also associated with a difference in incidence. ${ }^{31}$

When performing vitrectomy, the vitreous cutter ordinarily rotates more around the sclerotomy and reaches more extreme positions intraocularly compared with the light probe. This increase in manipulation induces wider dilatation of the sclerotomy and secondarily affects vitreous incarceration at the sclerotomy sites. However, in the current study, different degrees of manipulation of the sclerotomy sites inserted between the vitreous cutter and the light probe, depending on their function, did not seem to affect vitreous incarceration, and this has also been confirmed in an experimental model. ${ }^{34}$
The current study had some potential limitations. First, the number of patients was small. However, given that observing sclerotomies after removal of the cannula cannot be performed routinely, increasing the number of patients would be difficult. Second, the endoscopic observation used in the current study requires maintained infusion and another cannula for insertion of the endoscope. Preservation of irrigation from the infusion is necessary to avoid decreased intraocular pressure during observation. Although endoscopy can be used to observe the sclerotomy site intraoperatively, only one sclerotomy site where a cannula is removed first among the three cannulas can be observed during three-port vitrectomy. Thus, a sclerotomy site in which the infusion cannula is the last of the three cannulas to be removed cannot be observed as in animal models. ${ }^{10,13,19,20,27,31,34}$

The incidence of vitreous incarceration at the sclerotomy site was $6 \%$ in the current study. Considering previous studies, ${ }^{11,13,19-24,26-33}$ the incidence of incarceration at the sclerotomy site may be decreased as a result of increased knowledge and evolving instrumentation, which in turn will reduce complications such as endophthalmitis and rhegmatogenous retinal detachment.

\section{Disclosure}

The authors have no proprietary interest in any aspect of this study.

\section{References}

1. Fujii GY, de Juan E Jr, Humayun MS, et al. A new 25-gauge instrument system for transconjunctival sutureless vitrectomy surgery. Ophthalmology. 2002;109:1807-1812.

2. Fujii GY, de Juan E Jr, Humayun MS, et al. Initial experience using the transconjunctival sutureless vitrectomy system for vitreoretinal surgery. Ophthalmology. 2002;109:1814-1820.

3. Eckardt C. Transconjunctival sutureless 23 -gauge vitrectomy. Retina. 2005;25:208-211.

4. Lewis H. Sutureless microincision vitrectomy surgery: unclear benefit, uncertain safety. Am J Ophthalmol. 2007;144:613-615.

5. Hikichi T, Matsumoto N, Ohtsuka H, et al. Comparison of 1-year outcomes between 23- and 20-gauge vitrectomy for preretinal membrane. Am J Ophthalmol. 2009;147:639-643.

6. Lott MN, Manning MH, Singh J, et al. 23-gauge vitrectomy in 100 eyes: short-term visual outcomes and complications. Retina. 2008;28: $1193-1200$.

7. Gupta OP, Ho AC, Kaiser PK, et al. Short-term outcomes of 23-gauge pars plana vitrectomy. Am J Ophthalmol. 2008;146:193-197.

8. Territo C, Gieser JP, Wilson CA, Anand R. Influence of the cannulated vitrectomy system on the occurrence of iatrogenic sclerotomy retinal treas. Retina. 1997;17:430-433.

9. Tarantola RM, Tsui JY, Graff JM, et al. Intraoperative sclerotomyrelated retinal breaks during 23-gauge pars plana vitrectomy. Retina. 2013;33:136-142.

10. Lopez-Guajardo L, Benitez-Herreros J, Silva-Mato A. Experimental model to evaluate mechanical closure resistance of sutureless vitrectomy sclerotomies using pig eyes. Invest Ophthalmol Vis Sci. 2011;52: 4080-4084. 
11. López-Guajardo L, Vleming-Pinilla E, Pareja-Esteban J, Teus-Guezala MA. Ultrasound biomicroscopy study of direct and oblique 25-gauge vitrectomy sclerotomies. Am J Ophthalmol. 2007;143: 881-883.

12. Lin AL, Ghate DA, Robertson ZM, O'Sullivan PS, May WL, Chen CJ. Factors affecting wound leakage in 23-gauge sutureless pars plana vitrectomy. Retina. 2011;31:1101-1108.

13. Benitez-Herreros J, Lopez-Guajardo L, Camara-Gonzalez C, et al. Influence of incisional vitreous incarceration in sclerotomy closure competency after transconjunctival sutureless vitrectomy. Invest Ophthalmol Vis Sci. 2013;54:4366-4371.

14. Buettner H, Machemer R. Histopathologic findings in human eyes after pars plana vitrectomy and lensectomy. Arch Ophthalmol. 1977;95: 2029-2033.

15. Gosse E, Newsom R, Lochhead J. The incidence and distribution of iatrogenic retinal tears in 20-gauge and 23-gauge vitrectomy. Eye. 2012;26:140-143.

16. Tan HS, Mura M, de Smet MD. Iatrogenic retinal breaks in 25-gauge macular surgery. Am J Ophthalmol. 2009;148:427-430.

17. Chen SD, Mohammed Q, Bowling B, Patel CK. Vitreous wick syndromea potential cause of endophthalmitis after intravitreal injection of triamcinolone through the pars plana. Am J Ophthalmol. 2004;137: 1159-1160.

18. Hotta K, Hirakata A, Ohi Y, et al. Ultrasound biomicroscopy for examination of the sclerotomy site in eyes with proliferative diabetic retinopathy after vitrectomy. Retina. 2000;20:52-58.

19. López-Guajardo L, Pareja-Esteban J, Teus-Guezala MA. Oblique sclerotomy technique for prevention of incompetent wound closure in trans conjunctival 25-gauge vitrectomy. Am J Ophthalmol. 2006;141:1154-1156.

20. Inoue M, Shinoda K, Shinoda H, Kawamura R, Suzuki K, Ishida S. Two-step oblique incision during 25-gauge vitrectomy reduces incidence of postoperative hypotony. Clin Exp Ophthalmol. 2007;35: 693-696.

21. Shimada H, Nakashizuka H, Mori R, Mizutani Y, Hattori T. 25-gauge scleral tunnel transconjunctival vitrectomy. Am J Ophthalmol. 2006;142:871-873.

22. Singh RP, Bando H, Brasil OF, Williams DR, Kaiser PK. Evaluation of wound closure using different incision techniques with 23-gauge and 25-gauge microincision vitrectomy systems. Retina. 2008;28: 242-248.
23. Taban M, Sharma S, Ventura AA, Kaiser PK. Evaluation of wound closure in oblique 23-gauge sutureless sclerotomies with Visante optical coherence tomography. Am J Ophthalmol. 2009;147:101-107.

24. Teixeira A, Rezende FA, Salaroli C, Souza N, Sousa BA, Allemann N. In vivo comparison of 23- and 25-gauge sutureless vitrectomy incision architecture using spectral domain optical coherence tomography. J Ophthalmol. 2013;2013:347801.

25. Singh A, Chen JA, Stewart JM. Ocular surface fluid contamination of sutureless 25-gauge vitrectomy incisions. Retina. 2008;28:553-557.

26. Taban M, Ventura AA, Sharma S, Kaiser PK. Dynamic evaluation of sutureless vitrectomy wound: an optical coherence tomography and histopathology study. Ophthalmology. 2008;115:2221-2228.

27. Benitez-Herreros J,Lopez-GuajardoL, Camara-GonzalezC, Silva-Mato M. Effect of interposition maneuver during cannula removal on vitreous incarceration rate in vitrectomized eyes measured by ultrasound biomicroscopy. Curr Eye Res. 2012;37:809-812.

28. Nagpal M, Wartikar S, Nagpal K. Comparison of clinical outcomes and wound dynamics of sclerotomy ports of 20, 25, and 23 gauge vitrectomy. Retina. 2009;29:225-231.

29. Chen D, Lian Y, Cui L, Lu F, Ke Z, Song Z. Sutureless vitrectomy incision architecture in the immediate postoperative period evaluated in vivo using optical coherence tomography. Ophthalmology. 2010;117: 2003-2009.

30. Gutfleisch M, Dietzel M, Heimes B, Spital G, Pauleikhoff D, Lommatzsch A. Ultrasound biomicroscopic findings of conventional and sutureless sclerotomy sites after 20-, 23-, and 25-gauge pars plana vitrectomy. Eye. 2010;24:1268-1272.

31. Lopez-Guajardo L, Benitez-Herreros J, Camara-GonzalezC, Silva-Mato M Association of vitreous incarceration in sclerotomies with OCT, ultrasound biomicroscopy, and direct visualization. Ophthalmic Surg Lasers Imaging. 2012;43:S117-S122.

32. Zhengyu S, Fang W, Ying F, Qinghua Q. The experimental research of rabbit's sclerotomy sites undergoing transconjunctival sutureless vitrectomy. Curr Eye Res. 2007;32:647-652.

33. Inoue M, Ota I, Taniuchi S, Nagamoto T, Miyake K, Hirakata A. Miyake-Apple view of inner side of sclerotomy during microincision vitrectomy surgery. Acta Ophthalmol. 2011;89:e412-e416.

34. Benitez-Herreros J, Lopez-Guajardo L, Camara-Gonzalez C, PerezCrespo A, Silva-Mato M. Influence of sclerotomy use on vitreous incarceration in an experimental model of vitrectomized eye. Clin Ophthalmol. 2013;7:1471-1476.
Clinical Ophthalmology

\section{Publish your work in this journal}

Clinical Ophthalmology is an international, peer-reviewed journal covering all subspecialties within ophthalmology. Key topics include: Optometry; Visual science; Pharmacology and drug therapy in eye diseases; Basic Sciences; Primary and Secondary eye care; Patient Safety and Quality of Care Improvements. This journal is indexed on

\section{Dovepress}

PubMed Central and CAS, and is the official journal of The Society of Clinical Ophthalmology (SCO). The manuscript management system is completely online and includes a very quick and fair peer-review system, which is all easy to use. Visit http://www.dovepress.com/ testimonials.php to read real quotes from published authors. 